\#DLFteach • \#DLFTeach Toolkit: Lesson Plans for Digital Library Instruction

\title{
A Critical Introduction to Metadata through Dublin Core
}

Mackenzie Brooks

Published on: Sep 19, 2019

DOI: $10.21428 / 65 a 6243 c . d 57138 c c$ 


\section{Session Specifics}

One-shot session.

As a Digital Humanities Librarian with a metadata background, I frequently work with course and research projects that require knowledge of metadata standards and best practices. For most undergraduates, concepts like the CSV file format, ISO 8601 date formats, or the Getty's Art and Architecture Thesaurus are understandably foreign. It can be challenging to convey the value of these seemingly arbitrary sets of rules to students who are simply trying to complete a course assignment. And for an instructor of critical information literacy, teaching the mechanics of metadata is not sufficient. The following lesson plan is my attempt at introducing metadata principles in a way that is both critically-aware and relevant to the assignment at hand.

\section{Instructional Partners}

Disciplinary teaching faculty

\section{Audience}

Undergraduates in a humanities course

\section{Curricular Context}

A course with a digital project requiring knowledge of metadata, specifically Dublin Core. It could be combined with other instruction (Omeka, for instance) or stand alone.

\section{Learning Outcomes}

1. Recognize value of metadata and metadata standards.

2. Create consistent, thoughtful metadata in Dublin Core standard.

3. Analyze metadata through a critical lens. 


\section{Preparation}

- Consult with course instructor on assignment goals, timeline, and possibility of continued assessment.

- Review slides and lecture notes and customize lecture and activities for classroom context.

- Source images/artifacts for metadata creation activity.

- Prepare spreadsheet or Omeka instance.

\section{Materials}

- "Why Metadata Matters" slide deck, available in Additional Instructional Materials below. Important: Sample speaker's notes are included in the slide deck file. Please be sure to download and view the file.

- Artifacts for description - 1 unique artifact for every four students in the course. If working from digital objects, you can provide URLs, or print multiple copies so students can work simultaneously. You can also bring in printed or 3-D objects, such as vinyl records, books, pamphlets, photographs, or artwork. Numbering the artifacts helps track the metadata submissions for discussion. You can challenge the students by bringing in remediated artifacts (a photo of a piece of art) or artifacts with limited visible metadata.

- A Google form + spreadsheet with Dublin Core fields or a new Omeka instance, easily accessible by students. If using a spreadsheet, include a column for artifact number, all the Dublin Core fields, student name/initials, and even a field for citing sources or other comments.

\section{Session Outline}

\section{Introduction}

\section{5 minutes}

Introduce yourself, your goals for the session, and the agenda.

\section{"Why Metadata Matters" mini-lecture}

\section{0 minutes}


This lecture gives a brief history of the value of metadata through time, from the Library of Alexandria to Twitter hashtags. It is designed to illustrate that even if the word "metadata" is new to students, the concept is all around them. Slides and examples could easily be changed out for examples are that relevant to the course, the student body, the institution, or the instructor. The accompanying slides provide the following structure:

1. What is metadata? (slide 3 )

- Data about data - to establish a shared understanding, ask students to come up with metadata for the course text (title, author, publisher, etc).

2. Why Metadata Matters - this slide about the NSA monitoring phone calls reminds students that metadata is all around them.

3. Metadata for Libraries (slide 6)

- Library of Alexandria - provide a sense of scale and context. Libraries have been doing this for a long time! For more student engagement, ask them about their own book collections.

- Catalog card - bring us to more recent history. What are the core metadata elements for a book? What are the limits of this system?

- OPAC screen - prompt students to imagine the way metadata and discovery change after computers and the Web.

4. Google - question the value of metadata in a full-text world.

5. Twitter hashtags - hashtags as one example of unique labels.

6. My Little Pony tags - fun example on the value of tags and controlled vocabulary.

7. Metadata for Scholars (slide 13)

- For Better For Verse and Photogrammar are DH projects that serve as examples of the role of metadata in knowledge production and data visualization. Feel free to insert other projects for your context.

\section{Introduce Dublin Core and activity}

\section{5 minutes}

1. Explain Dublin Core (slide 15), giving a sense of its context and use as a metadata schema. As a practice round, ask students to verbally supply each field for the course text, guiding them to the right answers. Explaining concepts like language codes and date formats or vague fields like "relation" and type" will depend on your time, the level of the class, and the subject of the digital exhibit. It is not necessary for students to understand each field perfectly at this point. You will want some variety in their activity responses in order to prompt discussion.

2. Provide link to Google form or Omeka instance (the latter will require instruction on an Omeka item)

3. Pass out objects/artifacts. 


\section{Write your own! activity}

\section{0-15 minutes}

Students should select one object/artifact and write metadata in Omeka or the Google Form before moving on to a second. The subsequent discussion will be based on the inconsistencies of their answers, so it is best if 1 ) students complete several metadata records and 2) students don't share answers aloud.

\section{Discussion}

\section{$10+$ minutes}

Take a few minutes to review and project the results. If time permits, students could group by their chosen objects and discuss the differences in their metadata. If not, tackle the discussion questions on slide 17. The goal of the discussion should be to 1) recognize the importance of consistent metadata from a technical perspective 2) identify potential challenges in composing metadata and 3) illustrate the ways in which each author brings a different perspective to the project.

Sample questions:

- How did your metadata differ from your classmates'? Why might those differences matter?

- What was challenging?

- What choices did you have to make?

- What information is missing from the record?

\section{Conclusion}

\section{5 minutes}

Conclude with slide 18 to underscore the importance of keeping a critical eye during metadata creation. If time permits, have students reflect with a one-minute paper

\section{Assessment}

Assessment will depend on your level of involvement with the class. If your involvement level is low, you can review the results of the activity and make verbal corrections to student work. If time permits, a one-minute paper could help assess the results of the discussion. If you plan to work with 
the class through the course of the project, you can address problematic metadata fields in later sessions or provide information for the disciplinary faculty member to pass along. Ideally, you could negotiate with the disciplinary faculty member to let you grade or review the metadata before the project is graded.

\section{Reflection}

This lesson is designed to be flexible to the type of course, the level of involvement, and the nature of your relationship with the other instructor. I have used a variation on this lecture and activity in my own full semester courses and in one-shot sessions for courses in which I have no other contact with the students. For example, in my own course, a first-year seminar on born digital archives, I gave students ample time to explore and describe a host of physical documents and objects brought in from my personal collection. Discussion centered around the difference between print and digital objects with regard to research and metadata creation. Students described the objects in a Google form, then I projected the resulting spreadsheet so we could discuss the results. This session served as the initial training for creating metadata for their Archive-It project.

As a one-shot, I used this lesson during a single visit to a 4-week African American literature course doing a digital memorial project with Omeka. I preceded this activity by showcasing specific Omeka projects and discussing what makes a "digital memorial" as well as some specific instruction on Omeka.

As I have developed this lesson over time, I have found that teaching metadata through a critical lens brings relevancy and understanding to a topic that is easy to dismiss as needlessly detailed and pedantic. Students may not remember how to format a date or the difference between "type" and "format," but they will be able to recognize the value of metadata in the world around them.

\section{References}

NISO. Can There Be Neutrality in Cataloging? A Conversation Starter / NISO Website. https://www.niso.org/events/2018/04/can-there-be-neutrality-cataloging-conversation-starter. Accessed 10 Sept. 2018.

Peet, Lisa. "Library of Congress Drops Illegal Alien Subject Heading, Provokes Backlash Legislation." Library Journal, 13 June 2016, http://lj.libraryjournal.com/2016/06/legislation/library-of-congressdrops-illegal-alien-subject-heading-provokes-backlash-legislation/. Accessed 10 Sept. 2018.

Weinberger, David. Too Big to Know: Rethinking Knowledge Now That the Facts Aren't the Facts, Experts Are Everywhere, and the Smartest Person in the Room Is the Room. Basic Books, 2011. 


\section{Additional Instructional Materials}

\section{Slides}

"Why Metadata Matters"

\section{Contact Information}

Contributor Mackenzie Brooks can be reached at: mackenziekbrooks@gmail.com 